If we are to check our junior high schools according to the specific objectives as stated by Briggs it would seem that some constant, general courses are needed. At the same time, it would seem that the capacities, interests, and aptitudes of boys and girls can best be explored and developed through especially adapted, elective, unit courses, which serve also a second purpose of revealing to these boys and girls the possibilities of major fields of learning through material in itself worth while.

At this point Merle Prunty gave notice and explanation of the new National Honor Society sponsored by the Department.

It would seem that it might have been well still further to define this subject, making it quite definite and specific, stating for what short unit courses are preferable. However, we shall consider it as it is.

George E. Myers, Professor of Vocational Education and Guidance, University of Michigan, read his paper entitled What Is the Responsibility of the Junior High School for Direct Vocational Training?

\title{
WHAT IS THE RESPONSIBILITY OF THE JUNIOR HIGH SCHOOL FOR DIRECT VOCATIONAL TRAINING?
}

\author{
George E. Myers, \\ Professor of Vocational Education and Guidance, \\ UNIVERSITY OF MiChigAN
}

In attempting to answer this question, one is immediately impressed by the different conditions to be found in different cities and even in different junior high schools of the same city. It seems wise, therefore, to give the question a concrete setting by considering it with reference to some particular city. This should serve the triple purpose of providing a more clear-cut discussion of the question, of suggesting a method of attack which may be applicable in case of other cities, and of presenting certain facts and conditions which are valuable for comparative purposes when the question is given attention in other cities. The city chosen for study is Detroit, which had in 1927-28 a total of 46,748 public school pupils in the seventh, eighth, and ninth grades, about 25,000 of these being in fourteen inter- 
mediate or junior high schools, and the remainder in eight-grade schools and four-year high schools.

In any fair consideration of the question before us it is necessary to keep in mind certain facts concerning these pupils and concerning young workers in industry and business. Most important of these facts are the following:

1. The median age of boys and girls entering the seventh grade of the Detroit schools in the school year 1927-28 was 12.52 years.*

2. The median age of those entering the ninth grade in the same year was 14.31 years.

3. The median age of those completing the ninth grade, the last grade of the junior high school, was, therefore approximately 15.14 years. Putting the matter in another way, about one-half of the pupils in the ninth grade reached at least 15.3 years of age before the opening of the next school year, 1928-29.

4. Because of retardation a considerable number of boys and girls in the seventh, eighth, and ninth grades became sixteen years of age before the opening of the next school year. This number cannot be determined accurately from the published retardation tables but is estimated at 2,154, which is 4.6 per cent. However, this seems low as in one intermediate or junior high school with an enrollment of 2,400 , largely of Polish extraction, it was found by careful investigation that between April 1, 1927, and April 1, 1928, there were 201 girls, or about 16.6 per cent of all the girls in the school, who were sixteen years of age. $\dagger$

5. The number of boys and girls who reach sixteen years of age while in junior high school seems likely to decrease rather than to increase. Persistent efforts are being made in Detroit, and the same is true in many other city school systems, to reduce retardation by grouping children according to ability and then modifying the program of work for the slower groups in such a way that the children may be saved from the bad psychological effects of repeated failure. The results of these efforts will show more and more in the next few years in reducing the number of older children in the higher grades.

* Statistical statements which are given here are based upon the 1928 report of the Detroit Board of Education.

$\nmid$ Robinson, Bertha'M. An unpublished study. 
6. Even with the enormous increase in senior high school attendance which has taken place in recent years there is and probably will continue to be, a large number who do not attend all-day school beyond the junior high school. In Detroit during the school year of 1927-28 the enrollment in the ninth grade was 15,307 , while in the tenth grade the number dropped to 10,386 . In other words, the difference between the ninth grade enrollment and that of the tenth grade was 4,921 , or 32 per cent.

7. Of those who complete the junior high-school grades and enter senior high school, many will not continue their education in allday schools more than one year longer. The enrollment figures for Detroit show a drop from 10,386 to 6,026 , a difference of 4,360 or 43 per cent between the tenth and eleventh grades. The enrollment of the eleventh grade, it may be added, was 60 per cent, 9,271 pupils, below that of the ninth grade.

8. Many retarded pupils drop out without entering the ninth grade. In Detroit the difference in enrollment of retarded pupils in the seventh and ninth grades was 1,489 , or more than one-third. At the same time the number of accelerated pupils increased slightly between these grades. In the junior high school to which reference has already been made in which were found 201 sixteen year old girls, only 50 of these remained at the end of the year covered by the study; and 37 others had been transferred to other day-schools. Nearly all of those who remained were in the ninth grade, hoping to complete the course. The drop-outs were mostly from the seventh and eighth grades.

9. Those who leave all-day school with no more than a junior high school education, that is, without going farther than the ninth grade include large numbers of boys and girls who are accelerated, or ahead of the normal grade for their age. To be sure, the percentage of retarded pupils who drop out between the beginning of the ninth grade and the beginning of the tenth grade is larger than the corresponding percentage for accelerated pupils; but the number of the latter who leave is surprisingly large. According to the Detroit figures for 1927-28, the retarded group entering the tenth grade is 43 per cent smaller than the same group entering the ninth grade; the in-grade-at-age group is 36 per cent smaller ; and the accelerated group is 27 per cent smaller. In actual numbers the decrease in accelerates 
between the ninth and tenth grades is 2,933 , which is more than twice as great as the decrease in retarded pupils, for the reason that the former are much more numerous in the ninth grade of the Detroit schools.

10. The extent to which pupils drop out of the junior high school, and the grade at which they drop out are determined largely by the compulsory education and child labor laws of the state. The large loss of retarded pupils from the junior high-school grades, the larger loss of all groups between the beginning of the ninth and tenth grades, and the still larger loss the following year, is accounted for by the fact that boys and girls in Michigan may not leave school and obtain employment permits until sixteen years of age, unless their earnings are necessary for support of themselves or their family. In states which permit full-time employment at fourteen or fifteen the age and grade at which large numbers drop out of school is probably lower.

11. The great majority of wage-earning occupations which may be entered by youth at sixteen years of age or under require relatively little skill or technical knowledge. The time necessary to acquire the needed skill and special knowledge is small. Moreover, these may usually be acquired to better advantage in connection with the job than in a school before the job is begun. Still further, the relatively few who, at this age, enter occupations for which extensive preliminary training in all-day schools seems practicable are scattered among so many different occupations that the number in most of these is too small to justify the organization of classes.

A study* of 1,338 continuation school boys and girls, fifteen and sixteen years old, mostly sixteen, in Detroit, made in 1921-22 illustrates these points. Of the boys, 198, or more than one-third of those reporting on this item, were engaged in some kind of messenger or delivery service. The next largest group were in sales work or other store work, largely in small grocery stores and drug stores. This group numbered 76 . The remainder were scattered among more than a hundred and twenty-five different kinds of work, the largest number doing the same thing, being 18, in printing. In each of 109 different kinds of jobs listed only one or two boys were employed. Of 753 girls, 346 were engaged in housework, either at home or for

${ }^{*}$ Crockett, Alex. C. and Clow, Jennie M. Occupations of Junior Workers in Detroit. 
wages; 44 were telephone operators; 40 , workers in tobacco factories; 34, grocery clerks; 32, general office workers (filing, etc.) ; 23 , laundry workers; 22 , stocks girls; and so on. Only 10 were bookkeepers and stenographers.

According to the judgments of the boys themselves 88 per cent of them were engaged in work which required not more than one month to learn, and 65 per cent in work which could be learned in one week or less. According to the judgments of the girls, 97 per cent were doing work which required not more than one month to learn, while 75 per cent thought they could learn to do their work in one week or less.

12. It is becoming increasingly difficult for youth to enter the skilled trades, for which some school systems provide direct training in advance of employment, even as apprentices, at less than eighteen years of age. This is due in part to the attitude of employers, in part to the attitude of labor organizations, and in part to social and welfare organizations which have fostered legislation for the so-called protection of youth from hazardous employment. The substitution of machine work for hand labor, which has been taking place so extensively in recent years, seems likely to make this difficulty greater in the years just ahead than it is today. In the Detroit study alrearly referred to, fewer than 60 of the nearly 600 boys reporting were found to be employed where they had opportunity to learn one of the well known skilled trades. The work of the printer, baker, butcher, and draftsman accounted for 33 of these. In this great metal trades center only 3 of these sixteen year old boys reported that their work gave them an opportunity to learn the work of the toolmaker and three more the work of the auto-mechanic. In the building trades in this city of more than a million population, 3 of the 600 were employed as painter's helpers, 3 in the same capacity in the plumber's trade, 2 in the electrician's, 2 in the steam-fitter's, 1 in the bricklayer's, and 1 in the carpenter's trade. The opportunities for sixteen year old girls in skilled occupations were, of course, fewer than for boys.

Here, then, we have a number of facts which must be taken into account in any thorough-going attempt to answer for Detroit the question which forms the subject of this paper. 
The median age of the boys and girls when they enter junior high school is about 12.5 years. Of those who start the ninth grade, onehalf are beyond 14.3 years. At the close of the junior high-school period, slightly more than one-half have passed their fifteenth birthday. In all of the junior high schools of the city a considerable number of pupils each year because of retardation reach sixteen years of age; the percentage for the city is probably about 5 but runs as high as 16.6 in one school which was studied intensively. Ability grouping and special curricula are tending to reduce this number. One third of these retarded pupils, 1,500 in round numbers, drop out between the seventh and ninth grades, and another 1,250 do not go beyond the ninth grade. Few accelerated pupils drop out during the junior high-school years; but between the ninth and tenth grades the loss of accelerates and in-grade-at-age pupils totals about 3,700. In other words, 3,700 of those not retarded close their schooling with the junior high school. And of all those who enter the tenth grade, 4,300 or more than 40 per cent will finish their schooling within a year. The point at which drop-outs become numerous is determined to a large extent by the compulsory education and employment permit laws of the state. Most of the jobs taken by boys and girls who drop out of junior high school or within a year after its completion, require little skill or technical knowledge. It is becoming increasingly difficult for a youth to enter a skilled trade, even as an apprentice at less than eighteen years of age.

In addition to these facts, one needs to have clearly in mind what is meant by the term, direct vocational training. Does it mean preparation to perform successfully the processes of a single occupation, for example, that of a plumber? Or are we thinking of preparation for those activities in which one engages as a wage-earner in contrast with preparation for those activities in which one engages as a consumer and citizen? In the one case, we are likely to think only in terms of training for skill in the performance of processes. In the other case, our thinking must be in terms of training for right attitudes towards work in general, towards some occupation in particular, towards employer, fellow workers, capital, labor, management, etc., as well as training for skill in process performance. It is in the latter sense that we are using the term, direct vocational training, to-day. The young worker who thinks of his job merely in terms of the wages it pays him, or whose prime concern is to do only 
enough to get by, or who is indifferent to the men who work near him, or who believes that raw materials and labor are the only factors which determine the cost of production of the article which he helps to make is often under a more severe vocational handicap than the one who starts work without previous training in the processes of his job.

With this background, let me present briefly what I think the junior high schools of Detroit should do with reference to the entire range of vocational interests and needs of their boys and girls, and then consider how much of this deserves to be called direct vocational training.

The first responsibility of the junior high schools in this important matter is to give the best assistance possible to their pupils in making suitable choices of occupations. It is not to be expected, of course, that all junior high school pupils will make a final choice of occupation. Many will hold open this question until later. Others will decide only upon a field of occupations. Others will change their choices later. But all should be expected to give the question of a suitable occupation serious attention under wise guidance. This applies to the boy or girl who is going through high school and college as well as to the one who will go no farther than the ninth grade. We have no right to send the former on, looking forward to a career chosen through caprice of childhood or a whim of father or mother, without doing our best to help him find out whether this career or some other is best suited to his capacities and interests and holds̄ greatest promise for his success and happiness. Nor are we justified in directing, or even in permitting, the latter to spend a lot of time in preparation for a particular trade or other occupation until we have given him the best assistance we can in choosing the occupation for which preparation is to be made. This, to be sure, is a problem of vocational guidance and cannot be discussed in detail here. It may well be noted in passing, however, that it involves a study of the large groups of occupations-agricultural, mining, manufacturing, transportation, trade, clerical, public service, professional service, domestic and personal service-in the seventh and eighth grades. It involves later a study of the opportunities and requirements of a considerable number of occupations which are of greatest local importance. It involves provision for a variety of exploratory experiences which have significance in discovery of vocational aptitudes 
and interests. It involves bringing together as complete information as possible conerning each pupil's personality traits. And it involves expert assistance for each pupil by the vocational counselor in evaluating occupational information and exploratory experiences in relation to personality characteristics.

The second responsibility, as I see it, is to aid each boy and girl before leaving the junior high school to work out a vocational plan for the future. Some will soon forget their plans, many will change them, a few will carry them through, but nearly all will profit by going through this process under the guidance of a wise counselor, and working for a time at least towards the realization of the plan. In case of the boy or girl whose choice of occupation requires graduation from senior high school and college, the plan would naturally be preliminary or tentative or in outline form only, with the expectation that it would be expanded and filled in as to details later. In case of one who expects to leave school at sixteen years of age but who wishes to become a skilled worker in some particular trade, machinist for example, the plan should include what special preparation is to be made before leaving school, where this is to be obtained, what kind of work to do after leaving school until he is old enough to obtain employment as an apprentice or helper in a machine shop, what continuation and evening school work to do preliminary to and during employment in the machine shop, and so on.

A third responsibility of the junior high school is to develop in its pupils a respect for all vocations and an appreciation of the importance of them all to human welfare and progress, and to build up in its pupils that attitude towards work and towards the various responsibilities and relationships of the worker already mentioned, without which the completest success and satisfaction in any occupation is impossible.

Achievement of these desired ends depends upon the understanding of some of the fundamental but simple facts and principles of economics; for example: how capital is produced; the relation of capital to production of goods; the interdependence of capital and labor; the relation of management to production; the dependence of production upon transportation; selling in relation to production; and others. Consideration of such questions as: What the employer pays for and has a right to expect in quantity and quality of service, 
in coöperation, and in loyalty; and how friendly relationships between fellow workers are mutually helpful contribute also to development of the desired attitude. And it should be kept in mind that the understanding and attitude discussed here constitute a vocational asset of decided value in any employee position, though the immediate value will be greater to those who are about to leave school for the purpose of entering employment.

The fourth responsibility of the junior high school in vocational matters is to make provision, either within its own organization or in a special vocational school, for certain of its pupils who are approaching sixteen years of age and who are not likely to continue their schooling much if any beyond the ninth grade, to obtain some preparation for specific occupations. In Detroit it seems to me that for boys these occupations should include the machinist's trade, automechanics, both of which are now taught in selected junior high schools and in a central trade school, drafting, printing, and several of the building trades including carpentry, plumbing, electrical work, bricklaying and painting and decorating. (Some of the building trades are now taught in a vocational school.) Probably more careful study would result in suggesting provision for classes in baking, lithographing, sheet metal work, and other trades, and for retail selling.

For girls the problem is more difficult. But, with so large a proportion of girls who leave school at sixteen years engaged in house work and in restaurants, cafes, and the like, a vocational course in home-making in its broader sense and in those aspects of domestic and personal service which center in the home and in the public eating place, would seem to be practicable for retarded groups. General office work and filing might be provided for those who complete the ninth grade but go no farther. Retail selling is another occupation which could be taught to older girls of the ninth grade.

Naturally the question immediately arises: How are either boys or girls going to obtain employment at sixteen years of age in the occupations for which training is provided? There are numerous opportunities for girls of this age in the occupations mentioned; but very few for boys, as we have seen. It would be possible, however, for a few of the boys to be placed in apprenticeships or in a coöperative training program even at sixteen; for others to continue 
their trade preparation in continuation schools while working at unskilled work, pending a chance for placement by the school system in apprenticeships; and for still others to continue their trade preparation in a full-time trade school until such time as they can be placed in apprenticeships.

It is assumed that those who would take these vocational courses do so only after careful guidance including exploratory experiences and expert counseling. It must be understood, also, that the vocational courses provided should be gentuinely vocational in character and not planned merely to provide convenient parking places for retarded boys and girls until they reach the age at which they may leave school. Of course it is not necessary that all of the courses should be of the same length. Some should extend throughout the school year; others might well be planned for one semester only; and others might cover still shorter periods.

All that I have proposed has to do directly with the vocational problems of junior high school boys and girls. But not all can be called direct vocational training. Of the four responsibilities presented, the first and second have to do with guidance preliminary to vocational preparation, whether the preparation is obtained in junior ligh school, senior high school or later. The last is definitely a vocational training responsibility.

It seems likely that when fully organized, such work as proposed might care for the pre-employment vocational skill and technical knowledge preparation of the 6,500 pupils in Detroit who do not go beyond the ninth grade. It must be expected, however, that many of these will continue to enter occupations for which no training in work processes should be provided by the school.

The third responsibility presented, that for developing right vocational attitudes, is also direct vocational training, in that it is concerned with preparation of youth for the activities of a wage-earner rather than for those of the consumer and citizen. This responsibility affects most directly the 6,500 mentioned above. It affects only slightly less directly the 4,300 others who complete the ninth grade but do not go beyond the tenth. And it affects, also, though less inımediately, the remaining 6,000 who continue their education further. This responsibility is ats yet an unaccepted and in most cases an unrecognized challenge to the junior high school. 
All that is here discussed is in the direction of bridging the gap between school and employment. The junior high school has done fine service in bridging the gap between the elementary grades and high school. Here is another gap, wider and more dangerous, which results in enormous social and economic waste every year. More or less directly it threatens all junior high-school boys and girls. While significant work is under way in many schools, the much needed bridge is still far from complete.

What May the Senior High School Demand of the Junior High School, read by Assistant Professor of Education T. T. Spaulding of the Graduate School of Education, Harvard University.

\section{WHAT MAY THE SENIOR HIGH SCHOOL DEMAND OF THE JUNIOR HIGH SCHOOL?}

\section{F. T. Spaulding,}

\section{Assistant Professor of Education, Harvard University}

There is a phrase which seems to epitomize in a few words the ambitions of many people-teachers and administrators alike-whose interests are in the junior high school. The phrase is freedom from the domination of the senior high school. I quote it from no one in particular: doubtless I have heard it, in just that form, from no one person. But the spirit which lies behind it is apparently more or less widespread. It is a spirit of resentment as well as of aspiration: resentment at suspected attempts by the senior high school to control the program of studies and methods of teaching in the junior high school, and aspiration toward a happier day when the junior high school may be completely free to work out its own salvation.

It is possible that both the resentment and the aspiration underlying this phrase are in certain respects unfortunate. I hold no special brief for the senior high school. But junior high schools have tended in numerous instances, I think, to seek a degree of freedom which can hardly be justified. In particular, they have slighted demands which the senior high school may properly make upon them. It is highly desirable that some agreement be reached as to how far the junior high school should actually be free from restriction.

In all fairness we need first to consider the major arguments upon which the junior high school bases its claim to freedom. The justice 